TRANSFORMAÇÕES NA CONCEPÇÃO DE UNIVERSIDADE, 0 CASO BRASILEIRO, E SEUS IMPACTOS NOS ESTUDOS LITERÁRIOS

\author{
TRANSFORMATIONS IN THE CONCEPT OF UNIVERSITY, THE \\ BRAZILIAN CASE, AND IMPACTS ON LITERARY STUDIES
}

Fabio Akcelrud Durão ${ }^{1}$

RESUMO: A crescente divisão social do trabalho intelectual tem levado à proliferação de sub(sub)-campos de estudo, que ganham em poder de caracterização de objetos aquilo que perdem de uma visão do todo, agora praticamente visto como anátema. O presente texto discute as mutações amplas pelas quais têm passado a ideia da universidade, para em seguida abordar reflexos dessa dinâmica no âmbito dos estudos literários, sob o pano de fundo do contexto brasileiro.

PALAVRAS-CHAVE: Universidade. Neo-liberalismo. Brasil. Teoria.

ABSTRACT: The increasing social division of intellectual work has led to the proliferation of sub(sub)-fields of study, which gain in the characterization of their objects that which they lose of the vision of the whole, now almost taken as anathema. This text first discusses the broad mutations through which the idea of the university, then it approaches the effects of such changes in the field of literary studies within the Brazilian context.

KEYWORDS: University. Neo-liberalism. Brazil. Theory.

\footnotetext{
${ }^{1}$ Departamento de Teoria Literária. Universidade Estadual de Campinas (Unicamp).
} 


\section{TRANSFORMAÇÕES NA CONCEPÇÃO DE UNIVERSIDADE, O CASO BRASILEIRO, E SEUS IMPACTOS NOS ESTUDOS LITERÁRIOS}

\section{INTRODUÇÃO}

Este artigo tem em sua base duas motivações complementares. A primeira é uma experiência profissional, a de ter sido eleito em 2014 presidente da Associação Nacional de Pós-Graduação e Pesquisa em Letras e Linguística (ANPOLL), uma posição que por si só, como que performativamente, obriga a uma visão de cima, à reflexão da área como todo, dentro do contexto brasileiro. A segunda foi a leitura de Akademische Elite (2007) e Akademischer Kapitalismus (2011), de Richard Münch, livros que fornecem um diagnóstico abrangente, persuasivo e sombrio do sistema acadêmico alemão em um mundo globalizado, interessantemente visto como periférico diante do norte-americano. O texto está dividido em três partes, que se afunilam: a primeira comenta livremente os livros de Münch, a segunda compara a sua descrição com a situação do campo das Letras no Brasil e a terceira volta-se para aspectos desse estado de coisas dentro do âmbito dos estudos literários.

Akademische Elite e Akademischer Kapitalismus possuem vários pontos em comum. O primeiro volume descreve os efeitos nocivos da implantação, na Alemanha, de um sistema universitário baseado no conceito de excelência; o último, a transição do modelo humboldtiano, que constitui a base da universidade moderna, para um neoliberal ou pósmoderno. Com efeito, essa transformação pode funcionar como núcleo a partir do qual tudo o mais se desdobra. A ideia de universidade segundo Humboldt - que viria a ser adotada como ideal para a academia norte-americana (Parsons \& Platt, 1973) - tem como principal característica a formação e manutenção de um espaço igualitário de conhecimento: os pesquisadores devem ter total liberdade para perseguir seus objetos de estudo segundo a lógica e o ritmo que tais objetos demandam. A sociedade, por meio do governo, sustenta a universidade sem exigir algo imediato em troca; ela delega o poder de auto-gestão aos 
acadêmicos, pois entende que o progresso do saber, a descoberta do desconhecido, não pode se dar de forma programada: não é possível prever o imprevisível. O financiamento ocorre $a$ priori, como um voto de confiança (Treuhänderschaft) de que os recursos empregados levarão a benefícios futuros, pois o saber gerado pela universidade pode resultar, mas não necessariamente, em benefícios para todos. Na história da ciência, descobertas obtidas sem um interesse específico, até mesmo por acaso, muitas vezes levaram a breakthroughs, à descoberta de novos horizontes de investigação. Neste modelo, portanto, a universidade participa do moderno regime de autonomização das diversas esferas da vida social: da mesma maneira que o direito não pode sofrer ingerência do governo, ou que a religião não pode interferir na arte, deve haver uma esfera na qual a busca pelo saber possa seguir a sua dinâmica própria, sem a influência da economia.

Sob essa concepção de universidade, os professores formam uma comunidade de especialistas, tanto dentro das faculdades quanto nas associações científicas. Os resultados da pesquisa são oferecidos como um dom à totalidade dos estudiosos de determinado campo, em troca da honra de poder pertencer ao seu seleto círculo. Esse aspecto comunitário é o cerne do modelo, pois embora exista uma competição subjacente pelo renome, pela fama entre os pares, não há falta de reconhecimento por parte do grupo de cientistas. Todos os estão em pé de igualdade para divulgar o conhecimento que desenvolveram e questionar livremente as contribuições propostas pelos outros. Se impera uma presunção de igualdade entre os participantes da comunidade científica, a oposição de base é aquela entre os que fazem parte e os que estão de fora. O ponto-chave nessa visão da academia, o momento decisivo, é o da inclusão do novato no grupo dos conhecedores. Todos aqueles rituais que hoje podem nos parecer sem propósito ou exagerados, adquirem sentido ao simbolicamente marcar a aceitação de alguém no meio dos pesquisadores de determinado campo. A defesa do doutorado, ou, no caso alemão, da Habilitation, seria o momento de transição, aquele no qual a pessoa deixa de ser um aspirante para ser tido como um igual dentre os sabedores. Subjacente a esse (por vezes difícil ${ }^{2}$ ) processo de acolhimento está a valorização da busca da verdade; é ela que explica o caráter quase transcendente do trabalho acadêmico, como se o que estivesse em jogo fosse algo de outro mundo, o que, em certo sentido, não deixa de ser verdadeiro.

Outra característica importante da ideia humboldtiana de universidade é a inseparabilidade entre ensino e pesquisa (e, dependendo do caso, extensão). Pedagogicamente, isso significa que, junto com a transmissão de um conteúdo específico, ensina-se uma postura inquisitiva em relação ao conhecimento. Aprender passa a significar a capacidade de questionar determinado objeto, o que, é claro, pressupõe a sua anterior apreensão. O saber, aqui, é algo em constante movimento, por mais lento ou paulatino que ele seja, e a posição do sujeito em relação ao objeto de ensino/investigação é uma de interioridade ou intimidade: justamente por ser algo que domino e interrogo, que manuseio da maneira que me parece mais adequada, estabeleço uma proximidade para com ele. Isso é o contrário da escola, que lida com conteúdos estanques, produzidos por outros, que os alunos precisam memorizar; como se trata de algo estático, surge como pura exterioridade. Por fim, é importante observar que essa atitude perante o conhecimento projeta um ideal crítico de pessoa e de cidadão, pois quando extrapolada de seu campo específico ela pode converter-se em visão de mundo, em uma disposição questionadora, que não aceita as coisas simplesmente por serem o que são.

O segundo modelo, aquele que vem se impondo nas últimas três décadas, é caracterizado pelo enfraquecimento da auto-regulação por meio da comunidade científica. Um passo decisivo para tanto foi o desenvolvimento e implementação do New Public

\footnotetext{
${ }^{2}$ Pense-se nos diversos casos de diversos pensadores de primeira ordem que tiveram problemas com os seus doutorados ou livre-docências (Habilitationen), como Walter Benjamin, por exemplo.
} 
Management (NPM), que levaria para a universidade o ideal de eficiência do setor privado. O termo-chave aqui é "excelência". O processo é sem dúvida bem complexo em suas causas, mas seus resultados se fazem sentir na totalidade da vida acadêmica. Os seguintes aspectos podem dar uma ideia da profundidade da mutação por que passa a universidade:

a. No quadro anterior, os cargos administrativos eram preenchidos por professores, que após seus mandatos voltavam para a sala de aula e para o laboratório. Em muitos casos, as atividades burocráticas eram vistas como um estorvo, um mal necessário, um sacrifício que o pesquisador fazia para a comunidade, pois temporariamente estava obrigado a parar de estudar; por isso, frequentemente havia um rodízio. O corpo administrativo da universidade neoliberal é apenas em parte constituído por docentes e as idas e vindas entre cargos e pesquisa tornam-se uma exceção. Como os salários dos managers em geral é maior do que o dos professores, uma vida burocrática pode muito facilmente ser mais atrativa do que a da sala de aula e o doutorado amiúde aparece como fardo forçoso no caminho para mais dinheiro. Gradualmente vai formando-se uma disjunção, ou mesmo antagonismo, entre a casta administrativa e o corpo dos professores (cf. o desalentador quadro fornecido por Ginsberg [2011]).

b. Em decorrência do descolamento entre professores e administradores, estes perdem força no processo decisório. O recente caso de Steven Salaita é exemplar: após ter passado por um rigoroso processo de seleção e ter recebido o aceite oficial do comitê de busca, sua contratação foi barrada pelas instâncias superiores, pelo board of trustees, devido a tweets considerados antissemitas. ${ }^{3}$ Ao apelar para um code of civility, a administração da Universidade de Illinois em Urbana/Champaign deu motivos para suspeita de que a "civilidade" pode ser usada como instrumento de censura.

c. O New Public Management trouxe consigo uma mudança no financiamento das universidades e da pesquisa. Passa a ser consensual que o trabalho acadêmico deve procurar fontes externas de recursos e fazer, sempre que possível, parcerias com empresas, que assim tornam privados os resultados obtidos com financiamento ao menos parcialmente público. Mas mesmo as verbas estatais mudam de natureza; ao invés de se voltarem para a comunidade dos investigadores como um todo, elas agora pretendem concentrar-se nas universidades mais produtivas. O problema aqui é que, para o saber gerar o novo, ele precisa de multiplicidade, de pesquisas que ousam desbravar caminhos antes não pensados, e que normalmente fracassam, mas vez por outra levam à abertura de um novo horizonte. A investigação científica não pode ter medo do erro, e, consequentemente do desperdício de tempo e recursos - o que, é claro, vai contra a visão economicista. O resultado dessa política de financiamento é a formação de monopólios, carteis e oligarquias, pois quem mais recebe tem mais chance de mais receber.

d. No âmago desse processo está a quantificação da produção acadêmica. ${ }^{4} \mathrm{O}$ quanto a palavra "avaliação" tornou-se corriqueira demonstra o grau de penetração da nova concepção de universidade. Ela não faria muito sentido no modelo antigo, pois, como vimos, o controle era feito pelos próprios docentes e incidia primordialmente sobre o processo de aceitação de novos membros na comunidade e não sobre o que deveriam fazer. Quantificação e gerenciamento externo determinam-se mutuamente. Quando os números são alçados como parâmetro, instaura-se toda uma série de efeitos negativos. Só passa a ser digno aquilo que é mensurável e a organicidade da vida acadêmica fica

3 As publicações online sobre o caso são numerosas. Esta fornece uma boa perspectiva: http://markbbrown.com/2014/09/08/the-salaita-case-and-academic-governance/

${ }^{4}$ Mas note-se que mesmo "produção" já não é uma palavra de todo adequada. 
prejudicada. A docência deixa de ser parte integrante do ofício do pesquisador, e converte-se em punição, um castigo para quem publica menos, enquanto os mais produtivos são premiados com o distanciamento da sala de aula. Também há uma mudança no caráter formativo dos pesquisadores, pois estes agora perdem o valor que antes tinham, para converter-se em mão de obra auxiliar na publicações. $\mathrm{O}$ artigo transforma-se na unidade básica de valor e instaura-se a tendência para produções cada vez menores, os textos-salame, ou fast-food papers.

e. O espírito numérico não reina somente nas mentes dos burocratas e administradores; ele penetra na esfera intelectual sob a forma de capital simbólico (um termo ele mesmo desconfortável, mas aceito como neutro por quase todos, incluindo Münch). Com os rankings, a honra de fazer parte do mundo especial dos investigadores é substituída pelo prestígio de pertencer a uma instituição específica. A porosidade entre o capital simbólico e o real é extrema; a conversão de um no outro dá-se quase infalivelmente. Se a universidade sempre foi excludente, sob a égide neoliberal ela passa a espelhar muito mais fielmente as distinções de classe, contribuindo para a reprodução da desigualdade social.

f. Em relação às ciências humanas especificamente (algo que será retomado mais adiante), o princípio da quantificação representa um processo de colonização por parte das ciências exatas. O livro como forma é desvalorizado; os grandes estudos, como a Formação da Literatura Brasileira, de Antonio Candido (2014 [1959]), obras extensas que pretendem dar conta de um horizonte amplo, tornam-se praticamente inviáveis, devido ao tempo que exigem ${ }^{5}$

g. Como uma decorrência lógica natural, as associações profissionais perdem relevância, mesmo que mantenham representatividade, pois aquilo que representam, o corpo docente-pesquisador, enfraqueceu-se.

O novo regime acadêmico também promove uma metamorfose no interior das práticas estabelecidas. Considere-se dois exemplos: se a citação foi tradicionalmente concebida como um registro do débito do pesquisador com aquilo que foi elaborado anteriormente (mesmo que pela negação), com a precarização da ideia de comunidade ela muda de caráter. $\mathrm{O}$ gesto de citar passa a ser identificado a uma lógica de poder e usado estrategicamente; daí os pesquisadores de menor renome tenderem a mencionar com frequências os mais famosos (que hoje em inglês são chamados de star), para absorver algo do seu prestígio, ao passo que os pesquisadores no topo não precisam citar ninguém. Esta é apenas uma dentre várias manifestações palpáveis, presentes no cotidiano de qualquer professor universitário, que atestam as alterações por que têm passado a coletividade acadêmica. Em segundo lugar, pense-se no ritmo da escrita. Segundo o formato tradicional, a composição de ensaios ou capítulos era posterior à conclusão da pesquisa; na universidade contemporânea, os números a antecedem, pois há uma necessidade de publicar. Isso faz com que o artigo ou o livro apareçam como entidades vazias que precisam ser preenchidas por alguma espécie de conteúdo.

Porém em conjunção com a microestrutura do dia-a-dia há tendências abrangentes em jogo. É interessante aqui lembrar do diagnóstico de Bill Readings (1996) a respeito da ideia de excelência. Segundo ele, o "excelente" significa uma ausência de referência: ao invés de apontar para algum objetivo substantivo, um alvo tangível que as universidades deveriam alcançar, estabelece o mérito como resultado de uma comparação entre itens mais ou menos similares. O desaparecimento de uma finalidade palpável, para Readings, está relacionado ao

\footnotetext{
${ }^{5}$ É interessante perceber aqui como o ataque à ideia de obra em prol do texto, iniciada por Barthes em $1971 \mathrm{e}$ quase que transformada em senso comum desde então, adequa-se a esse estado de coisas. Para uma crítica da visão barthesiana, cf. Durão (2011b).
} 
enfraquecimento de projetos nacionais e do papel central que as universidades necessariamente desempenhavam neles como agentes de reprodução social segundo o modelo humboldtiano. É apenas quando não há mais uma imagem de desenvolvimento da nação sem dúvida associada à ideologia de uma cultura, povo ou mesmo raça, orgânica - que pode surgir um sistema universitário transnacional, como vimos, pautado por índices quantitativos, preocupado acima de tudo com a ideia de mensuração. Fica assim claramente marcado o pertencimento da universidade de excelência ao espírito da pós-modernidade, que desafia a moderna divisão da sociedade em diferentes esferas autônomas, regidas por leis próprias.

Münch sem dúvida está ciente dos problemas inerentes ao modelo anterior de universidade, porém não os salienta. Para obter uma imagem mais completa da situação atual seria necessário dissipar qualquer possível idealização do passado. A antiga estruturação da universidade possuía sérios vícios, que certamente facilitaram a sua queda. Como tinha algo de um espírito de guilda, resistia a mudanças drásticas, imbuindo-se de uma disposição conservadora. Tal conservadorismo vinha de mãos dadas com o personalismo, que levava a práticas de apadrinhamento e endogenia. O New Public Management tem uma postura agressiva em relação ao funcionalismo estatal; com sua ênfase na competição como estímulo à produtividade, parece ter como pressuposto uma preguiça endêmica ao setor público. Ora, ainda que falsa como panorama geral, a indolência não era algo tão raro. Por fim, a concepção de pesquisa na universidade moderna não se coadunava bem com a massificação do ensino superior, um ideal que alimentou as gerações pós-68. Talvez o problema aqui não fosse simplesmente a magnitude do número de ingressantes na universidade, mas o fato de que, com a popularização, as barreiras que a separavam a da sociedade tornaram-se mais débeis. Não é apenas o caso que a sociedade pode acusar a academia de ser elitista - os vetores podem ser invertidos e a academia pode criticar a sociedade de ser medíocre.

A pressão de uma tendência universal não impede que haja variações nacionais e regionais acentuadas. O caso brasileiro é interessante, porque exibe um campo de forças cognitivamente rico, no qual claramente coexistem dois opostos distantes: de um lado, um investimento considerável no ensino público superior, e, de outro, uma falta de resistência contra as piores práticas do ensino privatizado. Com efeito, essa distinção entre universidade pública e privada é o principal crivo para inicialmente caracterizar a academia no Brasil. Aquela, diferentemente dos Estados Unidos, é totalmente gratuita e fornece auxílio para os estudantes de baixa renda. A universidade pública tem se mostrado um importante veículo de mobilidade social, e muito do que vem ocorrendo de interessante na cultura brasileira dos últimos trinta anos de alguma maneira está ligado ela ${ }^{6}$. Por outro lado, o sistema privado, com a exceção de alguns poucos casos (como o sistema das Pontifícias Universidades Católicas, PUCs), só de muito longe assemelha-se a um conceito forte de universidade. Em sua quase totalidade, impera a sujeição a uma dinâmica de mercado, a busca do lucro acima de qualquer ideal de conhecimento (para o contexto norte-americano, cf. Donoghue [2008]).

A mercadorização do ensino superior é parte importante de um horizonte político e ideológico mais amplo; com efeito, ela pode servir como prisma para uma visão geral da sociedade. No Brasil, nos anos do governo neoliberal de Fernando Henrique Cardoso (01/01/1995-01/01/2003), o crescimento das instituições privadas foi impulsionado pela aprovação da Lei de Diretrizes e Bases da Educação Nacional (LDB), aprovada em 1996, que

\footnotetext{
${ }^{6}$ Talvez o exemplo mais paradigmático disso seja o caso de Paulo Lins, autor de Cidade de Deus (1997), um romance que mudou os rumos da literatura brasileira. Favelado, Lins formou-se em Letras pela UFRJ. Se tivesse que pagar pelo ensino, dificilmente teria conseguido concluir o ensino superior.
} 
estabeleceu os parâmetros sobre os quais as instituições de ensino superior (IES) podem voltar-se para a obtenção de lucro. Se é verdade, como argumenta Durham (2010), que a regulamentação impediu que fundações de ensino continuassem a mascarar seus lucros, ela também abriu o caminho a formação de poderosos conglomerados, com capital aberto e ações na bolsa de valores. Como prova disso Chaves dá o exemplo da Anhanguera que passou a ser a maior empresa do setor privado de educação superior [do Brasil], com 720 mil alunos matriculados (incluindo alunos de cursos de graduação e pós-graduação, profissionalizantes, presenciais e a distância). A maior parte das ações da Anhanguera Educacional pertence ao grupo Pátria Investimentos que, por sua vez, como registra seu web site, tem parcerias com os bancos de investimento norte-americanos Salomon Brothers e Oppenheimer (2010, p. 493).

Percebe-se aqui que o ensino superior não se diferencia qualitativamente dos outros níveis: a estrutura empresarial perpassa todos eles. De 2002 a 2008, o setor do ensino privado como um todo teve um crescimento de $25 \%$ passando de $\mathrm{R} \$ 44$ para $\mathrm{R} \$ 55$ bilhões (Chaves, 2010, p. 494). O ramo passa a equivaler às maiores empresas do país, como a Vale do Rio Doce (mineração) ou Petrobrás (petróleo). Ou, com outro corte temporal: de 1996 a 2007 houve no Brasil um crescimento de $161,2 \%$ no número de alunos matriculados no ensino superior; o setor privado aumentou em $221,2 \%$, e o público, em 68,7\%. Em 1996, as IES públicas representavam 22,9\% do total do país, em 2007, 10,9\%. Segundo o recente levantamento feito pela Federação Nacional das Escolas Particulares e pela Fundação Getúlio Vargas (2013), o número IES privadas aumentou de 1.934 para 2.112, entre 2005 e 2012. De acordo com os últimos dados disponíveis, em 2012 elas tinham 5.140.312 alunos matriculados.

É interessante notar que os governos sociais-democratas de Lula da Silva (20032010) e Dilma Rousseff (2011-) não reverteram o quadro incentivado por Fernando Henrique Cardoso: não houve força política para enfrentar o lobby das universidades privadas. Pelo contrário, a expansão do ensino privado tem sido fortemente subsidiada pelo governo federal. O Programa Universidade Para Todos (ProUni) tem como finalidade "a concessão de bolsas de estudo integrais e parciais em cursos de graduação e sequenciais de formação específica, em instituições de ensino superior privadas. Criado pelo Governo Federal em 2004 e institucionalizado pela Lei $\mathrm{n}^{\mathrm{o}} 11.096$, em 13 de janeiro de 2005 oferece, em contrapartida, isenção de tributos àquelas instituições que aderem ao Programa". ${ }^{7}$ Em 2012, o número total de alunos ativos no programa foi de 1.217 .179 , o equivalente a $23,68 \%$ do corpo discente da rede privada. Duas observações são necessárias aqui. Em primeiro lugar, vale ter em mente que esse crescimento da rede privada ocorreu sob o governo desenvolvimentista, de centroesquerda, do Partido dos Trabalhadores, com Luís Inácio Lula da Silva e Dilma Rousseff, que também investiu na expansão do sistema público. Isso demonstra a força das empresas de ensino e leva a pensar que em um ambiente mais propício à iniciativa privada, a progressão seria ainda mais acentuada. Além disso, é importante sublinhar que a expansão do ensino superior possui um aspecto positivo em si, quando comparada com sua simples ausência. $\mathrm{O}$ algo é melhor que o nada; a universidade, no Brasil, frequentemente desempenha o papel de complementação do ensino médio. No entanto, quando não se invoca a oposição entre alguma coisa versus o vazio, mas entre o bom e ruim, a conclusão é diferente. Apenas $17,79 \%$ dos docentes em IES privadas têm doutorado ${ }^{8}$. Se levarmos em consideração que esse percentual

\footnotetext{
${ }^{7} \mathrm{http} / /$ prouniportal.mec.gov.br/index.php?option=com_content\&view=article\&id=124\&Itemid=140

${ }^{8}$ Depois de uma defesa, ao cumprimentar o recém-doutor e desejar-lhe felicidade na vida acadêmica, recebi como resposta: "Fabio, por favor não conte para ninguém que defendi. Se o coordenador do curso [da faculdade privada na qual ensinava] descobre, perco o emprego." O Decreto $n^{\circ}$ 5.773/06 estabelece a obrigatoriedade, no ensino superior, de "um terço do corpo docente, pelo menos, com titulação acadêmica de mestrado ou doutorado". Muitas instituições particulares contratam o mínimo exigido de professores com pós-graduação e demitem todos que excedam esse piso.
} 
inclui as PUCs, que empregam majoritariamente doutores, ele cairá ainda mais se limitado apenas às instituições com fins lucrativos.

Paralelamente ao crescimento do ensino superior privado, no entanto, o governo federal tem investido na criação de novas universidades e campi, com o resultado de que o sistema encontra-se em expansão, ainda sendo possível conseguir ser contratado no interior apenas com o mestrado. Vale a pena contrastar rapidamente essa situação com a dos Estados Unidos, que atualmente passa por um acentuado processo de precarização do trabalho intelectual: "entre 1975 e 2007, os professores substitutos [adjuncts] cresceram de 43,2\% do corpo docente para $68,7 \%$. Isso coincidiu com a queda do número de professores com estabilidade [tenure] de 56,8\% para 31,2\%" (ORBESEN, 2013). Note-se bem, não se trata de lamentar um passado id́lico; é necessário reconhecer, como demostra Newfield (2003), que desde o começo a universidade americana esteve intimamente ligada à economia (além da religião) dos Estados Unidos. Isso não quer dizer, entretanto, que aquilo que está sendo imposto à universidade não possa, no final, desfigurar seu próprio conceito a ponto de se transfigurar em outra coisa.

Seja como for, a duplicidade da realidade brasileira faz com que seja difícil ter uma visão do todo: é como se dois universos paralelos, regidos por leis próprias, coexistissem lado a lado. Ou melhor, não dois mundos separados, mas em tensão, pois políticas governamentais específicas podem levar ao desmantelamento do sistema público e sua substituição por algumas poucas ilhas de pesquisa e uma multidão de escolões de terceiro grau.

\section{III}

As transformações por que passa a universidade atingem os estudos literários abrangente e profundamente, pois não é certo que a literatura adeque-se sem atrito a esse novo estado de coisas. No contexto brasileiro, o aspecto mais saliente é uma concepção cientifizante da literatura. As duas coisas não vão naturalmente de mãos dadas. A literatura inevitavelmente comporta um caráter não-conceitual que a ciência última não pode senão suspeitar como misticismo, mas que, colocado de forma correta, funciona como uma crítica a um certo ideal científico de clareza. Ou para dizer de modo algo polêmico: no rol dos conceitos caros à área, a pesquisa é inferior à crítica. $\mathrm{O}$ mesmo vale para a inutilidade do literário: algo artificial, feito por pessoas, mas cujo estudo, diferentemente do da sociedade, história ou civilizações, não se traduz em ganho, e que espontaneamente faz aparecer a pergunta "para quê tanto esforço?", mas que por sua vez pode funcionar como condenação do utilitarismo erigido a estatuto ontológico. Outro traço importante refere-se ao papel do tempo, que nos estudos literários e cumulativo e não, como na ciência, linear. Isso significa que o presente não abole o passado, mas o absorve, o que implica um processo bem mais demorado de reflexão. Em vista dessa ideia estruturante de sedimentação, não apenas a velocidade da pesquisa fica problematizada, mas a sua própria generalidade. É possível defender que ela não se adequaria à graduação, que os anos iniciais do ensino superior deveriam ser dedicados à formação de uma bagagem de leitura, uma espécie de repositório de experiência que ajudaria na elaboração de hipóteses de leitura posteriores (cf. Durão 2012). Uma outra zona de conflito entre o ideal de ciência e a natureza dos estudos literários refere-se ao caráter constitutivo da composição como dinâmica de descoberta. A escrita seria aquilo que, mutatis mutandis, corresponderia ao empirismo da ciência. A reprodutibilidade de determinado experimento, nos estudos literários, dá-se com a aplicação de uma ideia a um objeto diferente, o que é válido, do ponto de vista da ciência, mas empobrecedor na literatura. $O$ que confere confiabilidade a determinada interpretação, aquilo que faz com que pareça verdadeira, é a sua articulação como texto: é como fazer surgir o natural a partir de uma segunda natureza. 
Há, porém, dificuldades que se devem no contexto brasileiro mais especificamente. Consideremos os seguintes fatores: 1. profissionalização das letras é algo bem recente, coisa dos últimos trinta ou quarenta anos. 2. Em decorrência disso, não existe uma imaginação social da área. A ideia do cidadão médio, quando a tem, é a de que a faculdade produz professores do ensino médio, que ministrarão aulas de gramática e estilos de época. A maioria dos alunos percebe a existência de uma carreira de pesquisador na própria graduação; a ausência de um componente vocacional, de um desejo a priori (não importa quão vago) pelo objeto, encoraja o oportunismo. 3. A força da disjunção centro-periferia (mais sobre isso abaixo) faz com que a interlocução ocorra muito mais entre brasileiros e estrangeiros do que entre brasileiros e brasileiros - ou melhor: "interlocução" não é exato, porque nem Agamben, nem Žižek nem Spivak dão a menor importância para o que os brasileiros dizem deles. Seja como for o resultado de tudo isso é a fragilidade do campo de estudos, que surge como difuso, com pouca densidade e consistência. De passagem, isso ajuda a explicar a demonização das agências de fomento, em especial a Coordenação de Aperfeiçoamento de Pessoal de Nível Superior (CAPES), que é vista como uma entidade repressora e tirânica, o que absolutamente não é o caso. ${ }^{9}$

Mas o desconforto entre a nova cientifização dos estudos literários e seu objeto não estão restritas à démarche investigativa, mas perpassa igualmente as formas materiais nas quais acontecem as ideias. Artigos de revista, coletâneas de livros, congressos, pareceres, o papel das agências de fomento ${ }^{10}$ etc. poderiam ser analisados, assim como a cada vez mais estreita relação entre a universidade e a indústria cultural. Um exemplo, no entanto, deverá bastar, o da ideia de projeto. Para os estudos literários ela é estranha. Em primeiro lugar, ela geralmente inclui um período limitado e encoraja a pesquisa coletiva, o que por sua vez tende a apagar a individualidade da escrita. Daí não surpreender o virtual desaparecimento daqueles livros escritos individualmente e que necessitam de vários anos para a sua composição, impensáveis sob o regime do projeto. Em seu lugar surgem as de coletâneas de artigos por vários autores. Mas para além disso, porém, esse conceito pressupõe uma ideia autodelimitada de seu objeto, e um caráter palpável dos resultados, que contradizem o ideal ensaístico de boa parte da crítica. Para dizer de outra forma, a concepção corriqueira de "projeto" não consegue lidar nem com a leitura, nem com a escrita como procedimentos de pesquisa. Ou seja, quando lemos, abrimo-nos para associações que destroem a coerência do objeto inicialmente proposto; quando escrevemos, descobrimos o que sabíamos sobre ele. $\mathrm{O}$ projeto antecipa (e assim potencialmente constrange) justamente aquilo que surge como novo e desconhecido; para ser válido, e não fruto de má-fé ou wishful thinking, o projeto, a rigor, deveria ser escrito no final da pesquisa.

Um outro ponto de interesse, que nos servirá de desfecho, concerne a relação entre ideias e o modus operandi dos estudos literários cientifizados na universidade de excelência. A questão aqui é tentar relacionar uma forma de funcionamento da universidade e modalidades específicas de articulação conceitual. Note-se bem, não se trata de reduzir ideias às suas condições materiais de existência, nem postular qualquer espécie de determinismo. Ao invés, é mais proveitoso pensar que determinadas configurações de produção intelectual facilitam certos tipos de pensamento; quanto mais precário forem as condições do trabalho

\footnotetext{
${ }^{9}$ No sistema público de ensino, a tenure é praticamente imediata e são raríssimos os casos de demissão de docentes, nunca por falta de publicações. Além disso, a diferença salarial entre o ingressante na carreira e o professor titular é de aproximadamente um para três, o que mostra o quão pouco está em jogo do ponto de vista material e como aspectos psicológicos desempenham um papel importante como motor da carreira.

${ }^{10}$ É impossível não mencionar aqui a estapafúrdia situação na qual se encontra o financiamento dos estudos literários. Eles são baratos; no fundo, a única coisa de que precisam são livros. A maior parte dos editais voltados à área é supérflua, ocasionando diferentes modalidades de turismo acadêmico, enquanto as bibliotecas permanecem desamparadas.
} 
intelectual, tanto mais tentador será adotá-los. A hipótese aqui é a de que aquilo que ficou conhecido como Teoria (e não mais como teoria literária; cf. Durão [2011a]) pode ser visto como a manifestação mais adequada às transformações por que vêm passando os estudos literários. Isso pode ser comprovado, porque:

a. a Teoria é estruturalmente cosmopolita, antinacional por excelência. Como aquilo que a move é a contínua inovação conceitual, o seu escopo de validade será sempre universal, o que não impede a existência de estudos baseados na nação. Estes não serão lidos dentro uma tradição própria, mas possivelmente incorporados em uma teoria geral do nacionalismo, ou mesmo do pós-colonialismo;

b. a Teoria reproduz a divisão internacional do trabalho no âmbito das ideias. No Brasil, por exemplo, ela é a tecnologia que é importada para ser aplicada às manifestações culturais nacionais brutas - o mesmo que se faz com o café. Não é à toa que a sua consolidação foi paralela à emergência dos EUA como polo produtor e à decadência do pensamento nacional europeu (principalmente francês e alemão), que agora em grande medida faz a recepção de seus próprios teóricos via sua leitura anglo-saxã ; ${ }^{11}$

c. por meio dos Estudos Culturais, a Teoria explode o horizonte dos objetos e os limites das disciplinas. $\mathrm{O}$ custo disso é uma textualização do mundo, que pode ser vista como um imperialismo semiótico por pesquisadores de outras áreas, que continuam trabalhando normalmente;

d. a Teoria obtém a sua validade a partir de uma aposta no futuro. Ela vive seja da esperança de uma completude teórica a vir, seja de uma promessa de trazer inteligibilidade aos objetos. Em ambos os casos, trata-se de uma ilusão, que, no entanto, permite que muita energia seja despendida. A ideia de uma finalização da teoria encoraja o trabalho meta-teórico, que, cada vez mais distante do mundo das coisas, começa a parecer um sonho. Já na expectativa de esclarecer os textos, a articulação projetiva é diferente, pois justificativa da explicação é uma desculpa que encobre o fato de que o interesse maior está na formulação conceitual, não na dignidade das coisas.

A conclusão desse exposição em diferentes níveis é a de que a ação deve ser ela mesma diferenciada. Contra as mudanças que levam à mercadorização (tanto real quanto simbólica) da universidade é importante mobilizar-se politicamente, tanto por meio de partidos quanto por mobilizações coletivas; do ponto de vista do funcionamento interno da universidade, é importante identificar e combater as práticas e as ideias que fazem compatíveis os estudos literários com a academia do capitalismo tardio, que converte a literatura em algo pior do que não servir para nada.

\section{REFERÊNCIAS}

BARTHES, Roland. De 1'oeuvre au texte. In: Euvres Complètes, vol. 2. Paris: Seuil, 1994 [1971].

CANDIDO, Antonio. Formação da Literatura Brasileira. São Paulo: Ouro sobre Azul, 2014 [1959].

\footnotetext{
${ }^{11}$ O caso de Derrida talvez seja o mais representativo. É interessante pensar que o termo "desconstrução" é filho da academia americana. Deconstructing Harry (1997), de Woody Allen, foi traduzido em francês como Harry dans tous ses états.
} 
CHAVES, Vera Lúcia Jacob. Expansão da Privatização/Mercantilização do Ensino Superior Brasileiro: A Formação dos Oligopólios. In: Educação e Sociedade. Campinas, v.31, n.111, p.481-500, abr./jun. 2010.

DONOGHUE, Frank. The Last Professors. Nova York: Fordham U.P., 2008.

DURÃO, Fabio A. A crise nos estudos literários, hoje. In: Inês Signorini; Raquel Salek Fiad (Orgs.). Ensino de língua: das reformas, das inquietações e dos desafios. Belo Horizonte: Editora da UFMG, 2012.

. Teoria (literária) americana. Campinas: Autores Associados, 2011a.

. Do texto à obra. In: Alea, v.13, n.1, $2011 \mathrm{~b}$.

DURHAM, Eunice Ribeiro. A política educacional do governo Fernando Henrique Cardoso: uma visão comparada. Novos estudos - CEBRAP [online]. 2010, n.88 [cited 2015-02-24], pp. 153-179 . Disponível em: < http://www.scielo.br/scielo.php?script=sci_arttext\&pid=S0101$33002010000300009 \& \operatorname{lng}=\mathrm{en} \& n \mathrm{~nm}=$ iso $>$ Acesso em: 14 jul. 2014.

FUNDAÇÃO GETÚLIO VARGAS/Federação Nacional das Escolas Particulares. Números do Ensino Privado 2013. Disponível em: <

http://stat.correioweb.com.br/euestudante/Numeros_do_ensino_privado_2013.pdf > Acesso em: 14 jul. 2014.

GINSBERG, Benjamin. The Fall of the Faculty. Oxford: O.U.P., 2011.

LINS, Paulo. Cidade de Deus. São Paulo: Companhia das Letras, 1997.

MÜNCH, Richard. Akademischer Kapitalismus. Berlin: Suhrkamp, 2011.

Die akademische Elite. Berlin: Suhrkamp, 2007.

NEWFIELD, Christopher (2004). Ivy and Industry: Business and the Making of the American University, 1880-1980. Durham: Duke U.P..

ORBESEN, James. The Worst Time of the Year to Be an Adjunct Professor. The Atlantic. Disponível em: $<$ http://www.theatlantic.com/education/archive/2013/12/the-worst-time-ofthe-year-to-be-an-adjunct-professor/282314/ > Acesso em: 14 de jul. de 2014.

PARSONS TALCOTT \& GEORGE M. PLATT. The American University. Harvard: Harvard U.P., 1973.

READINGS, Bill. The University in Ruins. Harvard: Harvard U.P., 1996. 